I. М. Бутко

Державне підприємство «Центр державного земельного кадастру», Київ, Україна;

\title{
ФОРМАЛІЗАЦІЯ ТЕХНОЛОГІЇ ВИКОРИСТАННЯ ГЕОПРОСТОРОВИХ СТРУКТУР В СИСТЕМАХ ОБРОБКИ ГЕОПРОСТОРОВОЇ ІНФОРМАЦЇ
}

\begin{abstract}
Анотація. Предметом вивчення в статті є геопросторові структури в системах обробки геопросторової інформації. Метою є формалізація технології використання геопросторових структур в системах обробки геопросторової інформації. Завдання: аналіз основних завдань при прийнятті управлінських рішень, формалізація технології використання геопросторових структур в системах обробки геопросторової інформації, конкретизація основних об’єктів та морфізмів, що використовуються в системах обробки геопросторової інформації, представлення формальної моделі геопросторових інформаційних структур, формалізація операцій, що проводяться над геопросторовими інформаційними структурами. Використовуваними методами є: методи теорії категорій, теорії ймовірності, математичної статистики, системного аналізу, математичний апарат теорії матриць. Отримані такі результати. Формалізована технологія використання геопросторових структур в системах обробки геопросторової інформації. Представлені основні об'єкти та морфізми, що використовуються в системах обробки геопросторової інформації. Формалізована модель геопросторових інформаційних структур. Формалізовані операцій, що проводяться над геопросторовими інформаційними структурами. Висновки. Проведена формалізація технології використання геопросторових структур в системах обробки геопросторової інформації. Наведені основні об'єкти та морфізми, що використовуються в системах обробки геопросторової інформації. Представлена формальна модель геопросторових інформаційних структур. Проведена формалізація операцій, що проводяться над геопросторовими інформаційними структурами. Напрямками подальших досліджень $\epsilon$ : розробка теоретичних основ використання геопросторових структур в системах обробки геопросторової інформації у вигляді сукупності моделей, методів та інформаційних технологій побудови і використання геопросторових структур
\end{abstract}

Ключов і слов а: формалізація, технологія використання, геопросторова структура, геопросторова інформація, система обробки, теорія категорій.

\section{Вступ}

Постановка проблеми у загальному вигляді. Відомо $[1,2]$, що складність управління на любому рівні обумовлена об'єктивним протиріччям між вимогами до управлінських рішень в розрізі їх актуальності, достовірності, достатності, доступності, автентичності та суперечливістю умов, обмеженістю наявних ресурсів та недостатністю вхідної інформації для прийняття рішень.

Рішення - це відповідна реакція на внутрішні та зовнішні впливи, які спрямовані на розв'язання проблем та максимальне наближення до заданої мети [1]. Процес підготовки таких рішень має на меті формування повної сукупності альтернатив за результатами моделювання складної суперпозиції цілей, шляхів, ресурсів та результатів, що обумовлює необхідність збору та опрацювання великих обсягів різнопланової інформації. Управлінське рішення $\epsilon$ соціальним актом, що організовує та спрямовує в певне русло діяльність господарського суб'єкта, територіальної громади, району, області та виконує роль засобу, який сприяє досягненню мети, поставленої перед ним [1].

В теперішній час джерелом інформації для прийняття управлінських рішень $є$ сучасні системи обробки геопросторової інформації [3-5]. Використання геопросторової інформації, як правило, проводиться 3 метою прийняття рішень при виконанні інвентаризаційних, моніторингових, оперативних та дослідницьких заходів [3-5]. Використання систем обробки геопросторової інформації потребує математичної формалізації вирішення різнорідних завдань. Актуальним є завдання використання геопро- сторових ситруктур в системах обробки геопросторової інформації.

Мета статті - формалізація технології використання геопросторових структур в системах обробки геопросторової інформації.

Аналіз останніх досліджень і публікацій. Геопросторова інформація використовується, наприклад, органами державного управління при систематизації та приведенні земельних відносин до європейських стандартів [6]. В [6] зазначається, що у сфері земельних відносин автоматизація та інформатизація зменшують негативні процеси і явища, пов'язані зі зловживанням правовими недоліками в земельному законодавстві. Але математична постановка завдання обробки інформації геопросторової інформації в [6] не наведена.

Дослідження [7-10] показують, що створення високопродуктивних систем автоматизації та інформатизації має здійснюватися на базі інтелектуальних інформаційних технологій, основу яких складають системи підтримки прийняття рішення. В $[7,8]$ лише зазначається, що інтелектуальні системи повинні мати потужне математичне забезпечення у вигляді відповідних методів і моделей.

Системи підтримки прийняття рішень мають різні математичні базиси та дозволяють замінити людські ресурси на етапі обробки і структурування вихідних даних $[9,10]$. При цьому зазначається, що роль людини при прийнятті рішень залишається пріоритетною. Формалізації завдань обробки геопросторової інформації в [7-10] не наведено.

В $[14,15]$ зазначається, шо при заповненні в сфері земельних відносин важливу роль відіграють моделі формалізації права. Особливістю правових 
формальних моделей $є$ те, що вони повинні бути строгими і не допускати неоднозначного тлумачення. Застосування моделей формалізації в правознавстві сприяє повному і правильному сприйняттю інформації та забезпеченню строгих правових приписів.

В $[1,13]$ зазначається, що модель інформаційно-аналітичного забезпечення та супроводу управлінської діяльності передбачає виконання таких функцій:

- моніторинг ситуації. Реалізація цієї функції забезпечує аналіз всієї поточної інформації, яка надходить, іiі узагальнення, співставлення та надання у вигляді, який найбільшою мірою відповідає їх потребам. Матеріали аналізу джерел, поряд з іншими базами даних, є основою для підготовки аналітичних доповідей, записок, довідок та інших документів системи проблемно-орієнтованого інформування керівництва;

- збирання та первинне опрацювання інформації. Ці процеси представляють собою найбільш рутинну, трудомістку частину робіт. При незадовільній організації робіт із збирання та первинного опрацювання інформації аналітичні дослідження характеризуються низькою достовірністю та об’єктивністю, а їх результати, як правило, відображають суб'єктивну думку окремих аналітиківекспертів. Робота із збирання та первинного опрацювання інформації поєднує множину технічних та рутинних операцій у спільний процес, забезпечуючи приймання та реєстрацію інформації, яка надходить, перевірку цілісності та достовірності даних, систематизацію інформації за тематикою та адресою;

- експертно-аналітичне забезпечення. При реа- лізації цієї функції необхідно виявити найбільш компетентних фахівців у проблемних галузях та оцінити їх реальні можливості;

- створення системи автоматизованої підтримки аналітичних досліджень. Така система дає змогу оптимально організувати супровід інформаційноаналітичних досліджень 3 використанням спеціальних інформаційно-програмних засобів, які включають структурно-інформаційні, лінгвістичні та прикладні програмні компоненти.

В $[1,13]$ не наведена формалізація запропонованої моделі інформаційно-аналітичного забезпечення та супроводу управлінської діяльності.

\section{Основна частина}

Процес розробки та прийняття управлінського рішення, як правило, включає 7 стадій [1, 7-10]:

- аналіз ситуації та постановку мети;

- вибір й обгрунтування критеріїв ефективності та можливих наслідків рішень, які приймаються;

- розгляд варіантів рішень;

- кінцеве формулювання рішення;

- прийняття рішення та доведення його до виконавців;

- організація виконання рішень;

- контроль за виконанням рішень.

В системах обробки геопросторової інформації різного призначення на різних етапах проводиться обробка даних різного типу, які тим не менш, структурно ізоморфні - геопросторові інформаційні структури (ГеоIC).

Узагальнена схема системи обробки геопросторової інформації, що базується на ГеоІС, представлена на рис. 1.

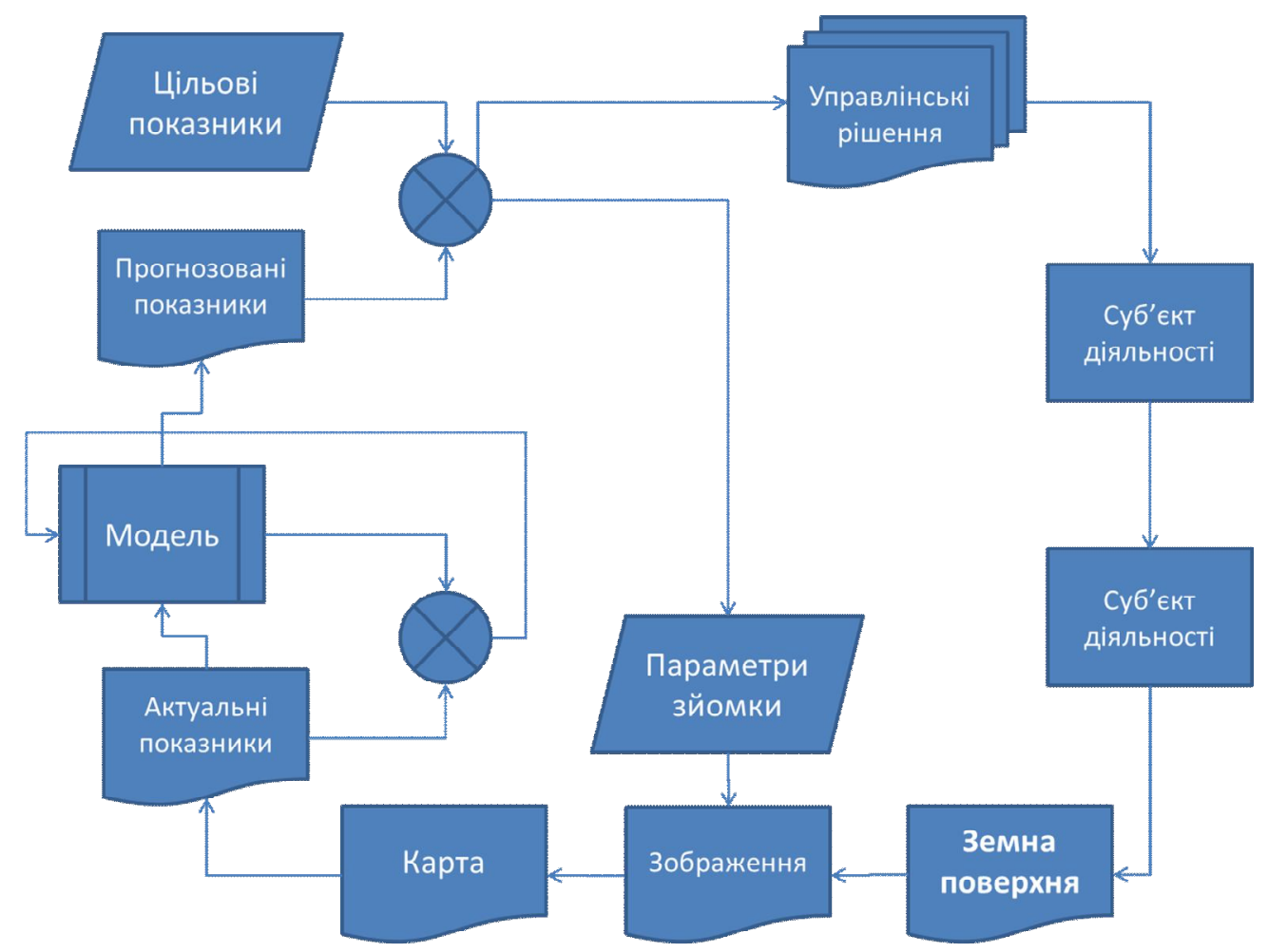

Рис. 1. Узагальнена схема системи обробки геопросторової інформації, що базується на ГеоIC 
Наступні твердження будемо проводити 3 використанням теоретико-категорійного апарату [14, $15,16]$.

Аналізуючи наведену на рис. 1 узагальнену схему системи обробки геопросторової інформації, можна виділити основні геопросторові інформаційні структури, що використовуються:

1) «поверхня» - TGeoSurface, представляє собою множину точок поверхні Землі, що задані своїми гео-координатами (географічна довгота і широта, висота над рівнем моря);

2) «зображення» - TImage, множина точок, кожна $з$ яких є вектором інтенсивності в різних спектральних діапазонах, точки задаються у прямокутній системі координат зображення; (задача геоприв'язки)

3) «карта» - ТМар, множина точок, кожна 3 яких є вектором геоознак (тип поверхні, зонування тощо), точки задаються геокоординатами;

4) «ознаки» - TFeature, множина ознак (площа, індекс вегетації тощо);

5) «рішення» - TDecision, множина управлінських рішень.

Надалі, ці ГеоІС будемо називати об'єктами, а можливі дії, при яких проводяться перетворення об’єктів - морфізмами. Суть цієї термінології буде зрозумілою з подальшого викладу.

Для введених вище об'єктів можливі такі морфізми, що дозволяють отримувати з одного об'єкту інший:

1) тотожні перетворення:

Id $_{\text {TGeoSurface: TGeoSurface -> TGeoSurface; }}$

Id TImage: TImage -> TImage;

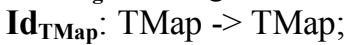

Id $_{\text {TFeature: }}$ TFeature -> TFeature;

Id $\mathbf{d}_{\text {TDecision: }}$ TDecision -> TDecision.

2) дистанційне зондування поверхні:

MRemoteSensing: TGeoSurface -> TImage;

3) картографування:

MMapping: TImage -> TMap;

4) рендеринг:

MRendering: TMap -> TImage;

5) виділення ознак:

MExtraction: TMap -> TFeature;

6) прийняття управлінських рішень:

MManagement: TFeature -> TDecision

7) діяльність:

MAction: TDecision -> TGeoSurface;

8) районування:

MZoning: TDecision -> TMap;

9) вибір ознак:

MSelection: TDecision -> TFeature;

10) вибір параметрів ДЗ3:

MControl: TDecision $->$ TImage.

Для вирішення проблеми подання різнорідних технологій програмної інженерії в єдиній формі, зручній для їх інтеграції та координації в рамках загального циклу проектування програмних систем останнім часом використовується математичний апарат теорії категорій, на базі якого побудовано універсальні теоретико-категорійні семантичні моделі цих технологій [17].
Відомо [18-23], що категорією називається паpa, що складається з класу об'єктів $A, B, C \ldots$ і класу морфізмів (стрілок) $f: A \rightarrow B, g: B \rightarrow C$, що зв'язують деякі пари об'єктів, які мають наступні властивості.

Для будь-якої пари морфізмів виду $f: A \rightarrow B$, $g: B \rightarrow C$ визначено добуток (композицію морфізмів) $g \circ f$, що є морфізмом $g \circ f: A \rightarrow C$. При цьомy:

- добуток є асоціативною операцією, тобто для будь-яких морфізмів $f: A \rightarrow B, \quad g: B \rightarrow C$, $h: C \rightarrow D$ справедливо, що

$$
h \circ(g \circ f)=(h \circ g) \circ f ;
$$

- для кожного об'єкту $A$ існує одиниця - тривіальний морфізм $i d_{A}$, такий, що для $f: A \rightarrow B$

$$
f \circ i d_{A}=i d_{B} \circ f=f .
$$

Наприклад, клас множин, що розглядаються в якості об'єктів, і клас відображень як морфізмів утворюють категорію множин Set, якщо під добутком розуміти операцію суперпозицію функцій.

Таким чином, для подальшого розгляду буде зручно ввести категорію CAT_GeoIS, об'єкти i морфізми якої було введено вище.

При переході від абстрактної ГеоIC (яка по суті $\epsilon$ декларативною) до конкретної ГеоІС (наприклад, «карти»), необхідно імплементувати іiі структури даних та методи (алгоритми) роботи з ними.

Зміни, що необхідно застосувати до ГеоІС при їх конкретизації, будемо називати, по аналогії з термінологією, яка у дещо іншому сенсі була введена у [22], імплементаторами. 3 кожною геопросторовою інформаційною структурою пов'язана множина допустимих імплементаторів. Нехай задано множину методів обробки геопросторової інформації (далі просто методів) $S$ і певну ГеоIC, яка може використовуватись методами з множини $S$. Позначимо через $X$ множину допустимих імплементаторів цієї структури.

Кожен імплементатор з множини $X$ перетворює абстрактну ГеоІС в конкретну інформаційну структуру, що використовується для методів з множини $S$.

Таким чином, формальну ГеоІС визначає відображення $\varphi: X \rightarrow S$. Це відображення в роботі будемо називати $S$-структурою з областю імплементаторів $X$.

Якщо $s \in S$ - деякий метод, то він буде сумісним по інтерфейсу з структурою $\varphi$ якщо $s \in \operatorname{Im}(\varphi)$, тобто якщо для деякого $x \in X$ маємо, що $\varphi(x)=s$. Нехай $S$ і $T$ - дві множини методів, тоді формальною технологією (у вузькому сенсі, далі - просто технологією) з $S$ у $T$ називається пара ГеоІС $\varphi: X \rightarrow S$ і $\psi: X \rightarrow T$ із спільною областю імплементаторів.

Технологія може бути застосована до методу $s \in S$, якщо цей метод сумісний по інтерфейсу з його лівою частиною - ГеоІС $\varphi: X \rightarrow S$, тобто, якщо для 
$x \in X$ маємо, що $\varphi(x)=s$. У цьому випадку результатом застосування технології є метод $\psi(x) \in T$, таким чином, формальна технологія (визначена вище) переводить методи 3 множини $S$ у методи 3 множини $T$. Відзначимо, що елемент $x \in X$ визначається рівністю $\varphi(x)=s$ неоднозначно, а отже, неоднозначно визначається і $\psi(x)$, тобто результат дії технології. Технологія показує лише можливі переходи від методу до методу, і з технологією може бути пов'язано кілька можливих методів [22].

Проведемо формалізацію операцій, що проводяться над геопросторовими інформаційними структурами. Зрозуміло, що множина імплементаторів одної ГеоІС може виступати в якості множини методів для іншої. Будемо говорити, що задана система ГеоIC, якщо визначено, які множини можуть виступати в якості множини методів і множини імплементаторів, і які відображення допускаються в якості ГеоІС. Будемо вимагати, щоб клас всіх таких відображень був би замкнутий щодо композиції та включав в себе тотожні відображення. Це, в свою чергу, означає, що задати систему ГеоIC - означає задати конкретну категорію $C$, наприклад, підкатегорію категорії множин і відображень. При цьому в якості ГеоІC можна вважати будь-який морфізм $\varphi \in C(X, Y)$ цієї категорії. У загальному випадку можна відмовитися від вимоги, щоб категорія $C$ обов'язково була б підкатегорією категорії множин, для отримання нетривіальних результатів достатньо, щоб вона належала до декартово замкнутих категорій - типу категорій, у яких кожен морфізм, що задано на добутку двох об'єктів можна природно ідентифікувати із морфізмом на одному із множників [18], [22-23].

3 точки зору програмування декартово замкнуті категорії реалізують інкапсуляції аргументів функцій, тобто кожен аргумент представляється об'єктом категорії і використовується як окрема сутність. Разом $з$ тим виразності декартово замкнутих категорій цілком достатньо, щоб оперувати з функціями способом, прийнятим в $\lambda$-численні, що робить їх природними категорійними моделями типізованого $\lambda$-числення. Тому декартово замкнуті категорії особливо широко використовуються у математичній логіці і програмуванні $[18,23]$.

Визначення. Категорія $C$ називається декартово замкнутою, якщо вона задовольняє трьом умовам:

1) у $C$ є термінальний об'єкт; $X \times Y$

2) будь-які два об'єкти $X, Y$ у $C$ мають добуток

Для будь-яких двох об'єктів $Y$ i $Z$ у $C$ існує експоненціал (експоненційний об'єкт) $Z^{Y}$.

Категорія, така, що для будь-якого іiї об'єкта, категорія об'єктів над ним є декартово замкнутою, називається локально декартово замкнутою [18].

Приклади декартово замкнутих категорій:

- категорія множин Set природним чином є декартово замкнутою категорією, оскільки функції $з$ однієї множини в іншу утворюють множину i, отже, $€$ об'єктом. Також в ній існують декартові добутки i термінальний об'єкт - синглетон;

- якщо G є групою, то категорія всіх G-множин $\epsilon$ декартово замкнутою;

- категорія всіх скінченних G-множин також $є$ декартово замкнутою;

- категорія Cat всіх малих категорій (i функторів, як морфізмів) є декартово замкнутою;

- елементарний топос $є$ декартово замкнутою категорією за означенням [18].

Визначення. Системою формальних ГеоIC називається декартово замкнута категорія $C$, в якій для кожної пари об'єктів $X$ і $Y$ визначена деяка множина $C_{S}(X, Y) \subset C(X, Y)$ морфізмів, причому виконується така умова технологічної замкнутості: якщо задані морфізми $\varphi: X \rightarrow S, \psi: Y \rightarrow S$ і $\sigma: X \rightarrow Y$ такі, що $\varphi=\psi \circ \sigma$, то $\varphi \in C_{S}(X, S)$ тоді і тільки тоді, коли $\psi \in C_{S}(Y, S)$.

$S$-структурою будемо називати морфізми $\varphi: X \rightarrow S$, де $X-$ довільний об'єкт категорії, $S$ методом - морфізм $\alpha: X \rightarrow S, \quad \alpha \in C_{S}(X, S)$. Об'єкт $X$ будемо називати областю імплементаторів $S$-структури $\varphi$.

Метод $\alpha: A \rightarrow S$ вважається сумісним по інтерфейсу з ГеоІC $\varphi: X \rightarrow S$, якщо для деякого морфізма $\beta: A \rightarrow X$ маємо, що $\alpha=\varphi \circ \beta$.

Визначення. Формальною технологією з $S$ в $T$ називається пара $\Gamma$ еоIC $-S$-структура і $T$-структура - із загальною областю імплементаторів, тобто пара морфізмів $\varphi: X \rightarrow S$ і $\psi: X \rightarrow T$. Така технологія діє на $S$-методи, перетворюючи їх у $T$-методи.

Технологія $(\varphi, \psi)$ вважається прийнятною для метода $\alpha: A \rightarrow S$, якщо цей метод сумісний по інтерфейсу зі структурою $\varphi$, тобто $\alpha=\varphi \circ \beta$ для деякого $\beta: A \rightarrow X$.

Результатом застосування технології до метода $\alpha$ в цьому випадку вважається метод $\psi \circ \beta: A \rightarrow T$ (цей морфізм $\epsilon$ методом в силу умови технологічної замкнутості) [22].

Вище вже відзначалося, що категорійною мовою можуть бути описані операції над ГеоIC і технологіями, що $є$ корисним в деяких задачах. Почнемо $з$ того, що властивості як ГеоIC, так і технологій, можуть бути розділені на дві групи.

До першої групи віднесемо властивості, засновані на тому, як влаштовані ці структури і технологiï.

До другої - властивості, що описують, якими методами ці ГеоІС можна обробляти і як ці технології діють на методи.

Властивості першого виду будемо називати внутрішніми, властивості другого виду - зовнішніми [22].

ГеоІС введено як спосіб опису для деякої множини методів, у той же час ГеоIC, що використовуються в реальних геопросторових інформаційних 
системах, можуть бути згенеровано набором процедур, які представляють собою певні синтаксичні конструкції. ГеоIC, як опис множини методів його обробки, і ГеоIC, як синтаксична конструкція - це об'єкти, що тісно пов'язані один з одним, але не тотожні.

Наприклад, різні за будовою ГеоIC можуть задавати ту ж саму множину методів. Аналогічно, технологія, так само як і ГеоIC, являє собою деяку синтаксичну конструкцію - набір інструкцій (програму), що реалізує певний алгоритм перетворення методів.

Зазвичай, внутрішні властивості ГеоIC і технологій перевіряються набагато простіше, ніж зовнішні властивості, оскільки перевірка перших вимагає розгляду самої ГеoIC, а перевірка других - розгляду множини (можливо, нескінченної) сумісних по інтерфейсу з нею методів. Однак, оскільки ГеоIC служить для опису множини методів, а технологія - для перетворення методів, то зовнішні властивості в деякому сенсі $€$ більш значущими. Тому важливим $\epsilon$ завдання встановити зв'язок між внутрішніми та зовнішніми властивостями. Деякі операції над ГеоIC природнім чином визначаються за допомогою зовнішніх властивостей, в той же час аналогічне внутрішнє визначення буває менш очевидним. Це буде показано нижче на прикладі композиції технологій. Теоретико-категорійний підхід часто дозволяє довести, що ті чи інші зовнішні операції зводяться до внутрішніх, останні ж можуть бути реалізовані за допомогою стандартних операцій теорії категорій.

Це дозволяє описувати відповідні операції в термінах верхнього рівня і включати їх в програми, що працюють зі знаннями, для яких реалізована відповідна категорія.

Наприклад, ГеоІС були введені як спосіб опису деякої множини близьких методів, отже, можна порівнювати ГеоІС, порівнюючи ті множини, які вони описують.

Нехай $\varphi: X \rightarrow S$ - деяка ГеоІС.

Позначимо через $S \varphi$ множину $S$-методів, сумісних із структурою $\varphi$.

Визначення. ГеоIC $\varphi \epsilon$ окремим випадком структури $\psi$, якщо $S \varphi \subset S \psi$.

Це визначення $€$ зовнішнім, надамо далі його внутрішній аналог.

Визначення. Нехай $\varphi: X \rightarrow S$ і $\psi: Y \rightarrow S-$ дві ГеоІС. Будемо говорити, що першу з них можна порівняти $з$ другою, якщо існує морфізм $\chi: X \rightarrow Y$ такий, що $\varphi=\psi \circ \chi$. У цьому випадку будемо також називати структуру $\varphi$ підструктурою ГеоIC $\psi$.

Останнє визначення повністю повторює дане раніше визначення сумісності по інтерфейсу метода зі структурою, яке тепер може розглядатися як окремий випадок сумісності двох ГеоIC.

Теорема. Якщо ГеоІС $\varphi: X \rightarrow S$ можна порівняти зі структурою $\psi: Y \rightarrow S$, то будь-який метод, що сумісний по інтерфейсу зі структурою $\varphi: X \rightarrow S, \epsilon$ сумісним і з ГеоІС $\psi: Y \rightarrow S$, тобто якщо одна ГеоІС є підструктурою іншої, то вона $є$ також іiї окремим випадком.

Доведення. Нехай структури $\varphi: X \rightarrow S$, $\psi: Y \rightarrow S$ і морфізм $\chi: X \rightarrow Y$ задовольняють умовами визначення. Якщо метод $\alpha: A \rightarrow S$ такий, що $\alpha \in S \varphi$, тобто для деякого морфізма $\beta: A \rightarrow X$ маємо $\alpha=\varphi \circ \beta$, то морфізм $\chi \circ \beta: A \rightarrow Y$ задовольняє рівності $\alpha=\psi \circ \chi \circ \beta$, звідки $\alpha \in S \psi$.

Обернене твердження, взагалі кажучи, не $є$ вірним, однак воно $\epsilon$ істиним у багатьох важливих частинних випадках.

Якщо перейти до розгляду формальної технології, то доцільно розглянути операцію композиції технологій, в якості прикладу того, як зовнішні операції, визначені на технологіях, зводяться до внутрішніх, що визначені на інформаційних структурах.

Визначення. Композиція двох технологій - це така технологія, яка перетворює метод $\alpha$ у метод $\beta$ в тому і тільки в тому випадку, коли існує такий метод $\gamma$, що перша технологія перетворює $\alpha$ в $\gamma$, а друга $-\gamma$ в $\beta$.

Для того, щоб це було можливо, будемо вважати, що в заданій категорії існують декартові квадрати. В [22] доведена теорема, що у заданій онтології звучить таким чином.

Теорема. Нехай $S \stackrel{\phi}{\longleftarrow} \underset{\sim}{\longrightarrow} S$ та $S \stackrel{\varphi}{\longleftarrow} Y \stackrel{\tau}{\longrightarrow} S-$ технології, а наступний вираз $€$ декартовим квадратом:

$$
\begin{aligned}
& Z \stackrel{\mu}{\longrightarrow} Y \\
& \downarrow \lambda \stackrel{\downarrow}{\downarrow} \quad \downarrow \varphi . \\
& X \stackrel{\sigma}{\longrightarrow} S
\end{aligned}
$$

Тоді технологія $S \stackrel{\text { фо }}{\longleftarrow} \underset{\sim}{\stackrel{\sigma \circ \mu}{\longrightarrow}} S \in$ композицією технологій $S \stackrel{\phi}{\longleftarrow} \underset{\sigma}{\longrightarrow} S \quad$ та $S \stackrel{\varphi}{\longleftarrow} Y \stackrel{\tau}{\longrightarrow} S$.

\section{Висновки і напрямки подальших досліджень}

Проведена формалізація технології використання геопросторових структур в системах обробки геопросторової інформації.

Наведені основні об'єкти та морфізми, що використовуються в системах обробки геопросторової інформації.

Представлена формальна модель геопросторових інформаційних структур.

Проведена формалізація операцій, що проводяться над геопросторовими інформаційними структурами.

Напрямком подальших досліджень є розробка теоретичних основ використання геопросторових структур в системах обробки геопросторової інформації у вигляді сукупності моделей, методів та інформаційних технологій побудови і використання геопросторових структур. 
СПИСОК ЛІтЕРАТУРИ

1. Управлінські рішення: евристичність, креативність, транспарентність: Навчальний посібник. / Під ред. М.П.Бутка. Ніжин: ТОВ «Видавництво «Аспект-Поліграф», 2008. - 428 с.

2. В.С.Філіпович Оперативний контроль поширення нелегального видобутку бурштину та оцінка збитків, заподіяних державі, за матеріалами багатозональної космічної зйомки. - Екологічна безпека та природокористування, № 4(20), 2015. - C. 92-97.

3. Shikhov, A.N., Cherepanova, E.S. and Ponomarchuk, A.I. (2014), Geoinformation systems: the use of GIS technologies in solving hydrological problems, a workshop, textbook. manual, Perm, $91 \mathrm{p}$.

4. Earth Observing System. High-Resolution Satellite Imagery. https://eos.com/ru/products/high-resolution-images/

5. Pustovarov, V. (2020), "Construction of information technology for development of knowledge base on identification of urban structures on digital space and aerial photographs in the urban environment monitoring", Advanced Information Systems, Vol. 4, No. 3, pp. 70-73, DOI: https://doi.org/10.20998/2522-9052.2020.3.08.

6. Шипулін В.Д. Система земельного адміністрування: основи сучасної теорії: навч. Посібник / В.Д. Шипулін. — Харків: ХНУМГ ім. О. М. Бекетова, 2016. -220 с.

7. Методи та системи штучного інтелекту / А. С. Савченко, О. О. Синельніков. - К. : НАУ, 2017. — 190 с.

8. Стеценко І.В. Моделювання систем : навчальний посібник / І. В. Стеценко. - Черкаси : ЧДТУ, 2010. - 399 с.

9. Методи та системи штучного інтелекту: навч. посіб. / укл. Д.В. Лубко, С.В. Шаров. - Мелітополь: ФОП Однорог Т.В., 2019. - $264 \mathrm{c}$.

10. Основи теорії прийняття рішень / О.І. Кушлик-Дивульська, Б. Р. Кушлик. — К., 2014. — 94 с.

11. Манько Д.Г. Технології формалізації права / Д.Г. Манько // Науковий вісник Міжнародного гуманітарного університету. - 2013. - № 5. - С. 18-21.

12. Радейко Р.І. Формалізація як метод дослідження правових явищ / Р. І. Радейко. — Львів: Інститут права та психології Національного університету «Львівська політехніка». — 2014. — № 8 (10). — С. 86-93.

13. Ткаченко В.В. Підхід до збору інформації щодо екологічної обстановки при виникненні надзвичайних ситуацій техногенного характеру / В.В. Ткаченко, О.Ю. Чередніченко, М.А. Вовк, С.І. Сршова // Проблеми інформаційних технологій. 2018. - № 23. - С. 219-226.

14. Маковейчук О. М. Інформаційна технологія побудови та використання візуальних інформаційних структур доповненої реальності. Сучасний стан наукових досліджень та технологій в промисловості. 2019. № 4 (10). С. 55-68.

15. Маковейчук О. М. Новий тип маркерів доповненої реальності. Сучасні інформаційні системи. 2019. № 3 (3). С. $43-$ 48.

16. Маковейчук О. М. Науково-прикладні основи побудови стійких маркерів доповненої реальності. Системи управління, навігації та зв'язку. 2019. № 6 (44). С. 133-137.

17. С. П. Ковалёв, Теоретико-категорный подход к проектированию программных систем, Фундамент. и прикл. матем., 2014, том 19, выпуск 3, 111-170

18. Seely, R. A. G. (1984). "Locally cartesian closed categories and type theory". Mathematical Proceedings of the Cambridge Philosophical Society. 95 (1): 33-48. doi:10.1017/S0305004100061284

19. Цаленко М. С., Шульгейфер Е. Г. Основы теории категорий. - М.: Наука, 1974.

20. Adamek J., Herrlich H., Strecker G. Abstract and Concrete Categories. — New York: ' Wiley and Sons, 1990.

21. Маклейн С. Категории для работающего математика. - М.: Физматлит, 2004.

22. Жожикашвили А.В. Категорная технология создания и развития интеллектуальных систем, основанных на знании. Информационные процессы. 2016. - № 4 (16). С. 312-332.

23. Bartosz Milewski. Category Theory for Programmers: The Preface. Post Date: October 28, 2014 [Electronic resource]. URL: https://bartoszmilewski.com/2014/10/28/category-theory-for-programmers-the-preface/ (Дата звернення: 19.01.2020).

Received (Надійшла) 31.10.2020 Accepted for publication (Прийнята до друку) 20.02.2021

\section{Formalization of technology of using geospatic structures in geospatial information processing systems}

\section{Butko}

Abstract. The subject matter of the article are geospatial structures in geospatial information processing systems. The goal is to formalize the technology of using geospatial structures in geospatial information processing systems. The tasks are: analysis of the main tasks in making managerial decisions, formalization of the technology of using geo-spatial structures in geospatial information processing systems, specification of the main objects and morphisms used in geospatial information processing systems, presentation of the formal model of geospatial information structures, formalization of operations conducted on geospatial information structures. The methods used are: methods of category theory, probability theory, mathematical statistics, system analysis, mathematical apparatus of matrix theory. The following results are obtained. formalized technology of using geospatial structures in geospatial information processing systems, the main objects and morphisms used in geospatial information processing systems are presented, formalized model of geospatial information structures, formalized operations conducted on geospatial information structures. Conclusions. Formalization of technology of use of geospatial structures in systems of processing of geospatial information is carried out. The main objects and morphisms used in geospatial information processing systems are given. A formal model of geospatial information structures is presented. The formalization of operations carried out on geospatial information structures has been carried out. The directions of further research are development of theoretical foundations for the use of geospatial structures in geospatial information processing systems in the form of a set of models, methods and information technologies for the construction and use of geospatial structures.

Keywords: formalization, technology of use, geospatial structure, geospatial information, processing system, category theory. 